\title{
Mathematics as a science of non-abstract reality: Aristotelian realist philosophies of mathematics
}

\author{
James Franklin \\ University of New South Wales, Sydney \\ Foundations of Science, 2021 \\ https://doi.org/10.1007/s10699-021-09786-1
}

\begin{abstract}
There is a wide range of realist but non-Platonist philosophies of mathematics naturalist or Aristotelian realisms. Held by Aristotle and Mill, they played little part in twentieth century philosophy of mathematics but have been revived recently. They assimilate mathematics to the rest of science. They hold that mathematics is the science of $X$, where $X$ is some observable feature of the (physical or other non-abstract) world. Choices for X include quantity, structure, pattern, complexity, relations. The article lays out and compares these options, including their accounts of what $\mathrm{X}$ is, the examples supporting each theory, and the reasons for identifying the science of $\mathrm{X}$ with (most or all of) mathematics. Some comparison of the options is undertaken, but the main aim is to display the spectrum of viable alternatives to Platonism and nominalism. It is explained how these views answer Frege's widely accepted argument that arithmetic cannot be about real features of the physical world, and arguments that such mathematical objects as large infinities and perfect geometrical figures cannot be physically realized.
\end{abstract}

Keywords: Philosophy of mathematics; Aristotelianism; Platonism; quantity; structuralism; pattern; Frege

\section{Introduction}

What is the nature of mathematical entities like numbers, sets and functions? According to Platonism (the "standard" or "full-blooded" or "objects" Platonism usual in the philosophy of mathematics), they are classical "abstract objects": acausal, atemporal objects existing necessarily in a Platonic realm, neither physical nor mental. (Linnebo 2009/2018; Brown 2008, ch. 2) According to nominalism, they do not exist at all; there are only physical objects, and 
the mathematical language that appears to refer to mathematical objects is just a language of science, or manipulation of formal symbols, or fictions, or method of deducing one contentful proposition from others. By Ockham's Razor, there is no need to postulate abstract entities once those tasks are accomplished.

Aristotelian realist philosophy of mathematics points out that Platonism and nominalism do not exhaust the possibilities. Numbers (etc) could exist but in a way other than as Platonic entities - for example as properties of physical objects, such as their structural or relational or quantitative properties. Any such view, any "immanent mathematical realism (any realism acceptable to a physicalist)" (Irvine1990), falls within the tradition of Aristotelian realism, in the wide sense of a non-Platonist realism according to which a presumptive reality exists "in the things themselves". Aristotelianism's commitment only to naturalistically acceptable scientific entities makes it possible to claim that it is "the current philosophy of mathematics that fits best with what is known about minds and science." (Thagard 2019, 274) A search for such an alternative will become attractive if it is felt that Platonism and nominalism have reached an impasse, and if considerations within mathematics, especially applied mathematics, bring to the fore mathematical properties of the (non-abstract) world such as symmetry, ratio and continuity.

\section{The mathematical aspects of reality}

While the Platonist-nominalist debate is strictly an internal debate in philosophy, Aristotelian realists also urge that the physical world can be easily seen to have mathematical properties, which must be the subject of some science. If we just look at how mathematics works (especially applied mathematics), free of philosophical preconceptions, it should be possible to see what properties of reality are mathematical (rather than physical, biological and so on) and form the true subject-matter of mathematics.

Imagine the Earth in the Jurassic Era, before there were humans to think mathematically and write formulas. There were dinosaurs large and small, trees, volcanoes, flowing rivers and winds ... Were there, in that world, any properties that we would recognize as being of a mathematical nature (to speak as non-committally as possible)? That is, were there, among the properties of the real things in that physical world, some that we would naturally recognize as mathematical (over and above physical, chemical and biological properties)? 
There were many such properties. Symmetry, for one. Like most higher animals, the dinosaurs had approximate bilateral symmetry. The trees and volcanoes had an approximate circular symmetry with random elements - seen from above, they look much the same when rotated around their axis. But symmetry, whether exact or approximate, is a property that is not exactly physical. Non-physical things can have symmetry; arguments and palindromes, for example, have symmetry if the last half repeats the first half in the opposite order. Symmetry is an uncontroversially mathematical property, and a major branch of pure mathematics - group theory - is devoted to classifying its kinds. When symmetry is realized in physical things, it is often very obvious to perception - even animals as primitive as bees can perceive symmetry. (Giurfa et al. 1996) Symmetry, like other mathematical properties, can have causal powers, unlike abstracta as conceived by Platonists.

Another mathematical property, which like symmetry is realizable in many sorts of physical things, is ratio. The height of a big dinosaur stands in a certain ratio to the height of a small dinosaur. The ratio of their volumes is different - in fact, the ratio of their volumes is much greater than the ratio of their heights, which is what makes big dinosaurs ungainly and small ones sprightly. A given ratio is something that can be the relation between two heights, or two volumes, or two time intervals; a ratio is just what those relations between different kinds of physical entities share, and is thus a more mathematical property than the physical lengths, volumes, and times themselves. Ratio is what we measure when we determine how a length (or volume, or time, etc) relates to an arbitrarily chosen unit. It is one of the basic kinds of number.

Properties of reality like symmetry and ratio and others (such as flows, order relations, continuity and discreteness, alternation, linearity, feedback, network topology) - which are measurable, perceivable and causal, like other scientific properties - must be the subject of some science. That science is mathematics (or at least part of mathematics).

With that intuitive approach to Aristotelian realism laid out, let us return to how it relates to the main alternatives in the philosophy of mathematics.

\section{The Platonist-nominalist impasse}

It is not possible to consider all the reasons for and against Platonism and nominalism, but a brief survey of the standard objections raised by each against the other will help explain the opportunities for the Aristotelian alternative. 
Platonists argue, against nominalism, that mathematics is indispensable to science and reference in science to mathematical entities is ineliminable. (Colyvan 2001; Linnebo 2009/2018, section 2) Aristotelians accept that argument, but point out that it does not imply anything about the nature of mathematical entities, in particular that it does not imply they must be classical abstract objects. (Newstead and Franklin 2012) Indeed, Colyvan, the leading proponent of the indispensability argument, includes Aristotelian realisms among the positions to which the argument applies. (Colyvan 2001, 4; Pincock 2012, ch. 9) If therefore Aristotelian realism proves more acceptable than Platonist on general metaphysical grounds, it can claim all the support that Platonism receives from the indispensability argument.

Nominalists argue, against Platonism, that Platonists fail to explain how there can be epistemic access to abstract objects. If they are acausal, how can they affect us so that we can come to know them? (Liggins 2010) If on the other hand we posit them to play some theoretical role, that is quite unlike positing atoms, which play the role of causing the observations which they are intended to explain; without a causal role, it is hard to see what role Platonist entities play beyond a purely linguistic one. (Cheyne and Pigden 1996) Aristotelians offer to show that at least some of the objects of mathematics, properties such as symmetry and quantity, are straightforwardly causal and perceivable.

Nominalists argue too that abstract objects are ruled out by naturalism and are not needed in any other area of science, so mathematics would be anomalous in requiring their existence. (Papineau, 2007/2015 section 1.8) Aristotelians agree with that argument too, and offer to exhibit mathematics as having a naturalistically acceptable subject matter.

Nominalists and Platonists both also argue that their opponents give no satisfactory account of applied mathematics - of the "unreasonable effectiveness of mathematics" and its role in explaining physical phenomena. (Steiner 1998; Pincock 2012, ch. 8) Platonists, say nominalists, fail to explain how truths about abstract objects can inform us about those aspects of the real world typically studied by applied mathematics, like continuous flows and symmetries. Nominalists, say Platonists, have the same problem: why should manipulating formal symbols or fictions inform us about those same real entities and allow us to establish contentful and useful truths about them? Aristotelians offer to supply a view of mathematics as inherently applied - as much inherently applied as physics or biology - since it is about properties possessed in any case by physical things (and whatever other things there may be).

In addition, Aristotelians believe that Platonists and nominalists make a common error: of regarding everything that exists as a particular (whether abstract or concrete). Aristotelians argue that science typically deals in universals - for example the relations between mass, 
distance and force described in Newton's law of gravity - and that mathematics should follow suit by, for example, studying properties like symmetry and continuity and what progressions have in common. Universals are not "things" (particulars) that come into and go out of existence (though particulars can come to and cease to have universals). Thus the truths about them, such as the transitivity of greater-than (if A is greater than B and B is greater than C, then $\mathrm{A}$ is greater than $\mathrm{C}$ ) can be eternal and necessary. Aristotelianism is thus not a simple empiricism, despite claiming that mathematics is directly about reality.

\section{The Aristotelian spectrum in the philosophy of mathematics}

Any Aristotelian realism about the objects of mathematics faces certain well-known problems (to be considered more fully in the last section). For example, some of the objects of mathematics appear to be too big to fit into physical reality, such as the huge and probably uninstantiated higher infinities. And as noted by Aristotle himself, mathematicians appear to speak of idealizations like perfect circles which likewise may not be literally instantiated. But then Platonism and nominalism face well-known objections too. The first thing is to lay out the options and their prima facie strengths. That has not so far been done - for example, the extensive classification of realist philosophies of mathematics in Balaguer's Platonism and Anti-Platonism in Mathematics (1998, 11) instances only Mill under (non-mentalistic) "realistic anti-Platonism". Only when it is done can there be a fair contest as to which philosophy of mathematics can best establish itself and reply to objections.

The book of Franklin (2014a, summary in Franklin 2011) defended one particular version of Aristotelian realism in the philosophy of mathematics, the view that mathematics is the "science of quantity and structure" (those two being interpreted as real properties of nonabstract reality). One reviewer rightly pointed out that "One of the beauties of the Aristotelian position introduced is that it has far more scope for internal variation than either Platonist or nominalist alternatives." (Jones 2015) Indeed there have been a few other recent presentations of explicitly Aristotelian realist philosophies of mathematics (Jacquette 2014; Gillies 2015; Knapp 2014; Hossack 2020). The aim of the present article is to clarify the range of Aristotelian realist philosophies of mathematics and explain their virtues as an alternative to Platonism and nominalism.

It is the basic question, "What is mathematics about?" that distinguishes among varieties of Aristotelianism, as well as distinguishing Aristotelianism from its competitors. Platonism and 
nominalism have simple answers to that question. Platonism holds that mathematics is about abstract entities. Nominalism holds that mathematics is not about anything at all (but is a language or the manipulation of formal symbols or a fiction or similar). Aristotelianism, on the other hand, aims to exhibit mathematics as the science of some aspect of the (non-abstract) world, opening the way to various choices about what that aspect is.

So as to concentrate on essentials, two matters are left aside although they are necessary for a full appreciation of the Aristotelian realist alternative. The first is metaphysics strictly speaking. Platonism and nominalism have clear and well-developed metaphysical positions in general, to which Aristotelianism must present an equally clear and well-developed alternative. That has been done, in general metaphysics outside the philosophy of mathematics. (A classic attempt is Armstrong 1997; tutorial in Franklin 2014a, ch. 1; in the philosophy of mathematics context in Jacquette 2014) Those general theories, though necessary to underpin an Aristotelian position, are outside the scope of the present article, which concerns Aristotelian approaches to the philosophy of mathematics specifically. For present purposes we can adopt a minimal and commonsense realism about properties of physical reality: the way in which physics takes for granted the reality of its objects such as mass and charge is the way in which Aristotelian realism will take the reality of ratios, patterns, symmetries or whatever it claims to be the objects of mathematics. What is necessary in the first instance for Aristotelianism to become a live option in the philosophy of mathematics is an account of what aspects of (non-abstract) reality it could be about, that is, what properties are mathematical.

The second topic to be left aside is epistemology. Prima facie Aristotelianism has an advantage over Platonism, since (many) properties of physical objects can be perceived, whereas it is widely argued, as above, that Platonism has a severe "access" problem, as its abstract objects cannot have causal effect on human brains. (Franklin 2014a, part II; Jacquette 2014, section 6; Lehrer Dive 2003) On the other hand, it may be harder to explain proof, which appears to distinguish mathematical from scientific epistemology. However, that too is beyond the scope of the present discussion of positions on the objects of mathematics.

Furthermore, existing Aristotelian positions have not developed metaphysical or epistemological views at length (with the exception of Franklin 2014a, based on Armstrong) and so have not disagreed about them. It is the question "What is mathematics about?" that separates different positions.

We will treat several theories that have been put forward of the form "Mathematics is the science of X" (where $\mathrm{X}$ is something that could be realized in the non-abstract world: patterns, structure, relations, quantity ...). For each theory, these questions need to be addressed: 
- What are the intuitive reasons and examples suggesting the theory?

- Have its defenders given a precise definition or characterization of $\mathrm{X}$ ?

- What are the arguments for seeing (all or much) of mathematics as included in X?

- What are the reasons for thinking that the science of $\mathrm{X}$ is included in mathematics?

- What is each theory's account of natural numbers? (Since all offer something on this basic question)

We include brief discussion, where applicable, on the prospects of each theory and on such questions as the compatiblity of views and whether some are really relabellings of others. In general, the suggested subject-matters of mathematics all have some credibility, and an eirenic rather than combative attitude to different claims is indicated. We will briefly compare the theories after surveying them.

Note however that the question "What real aspects of the world, if any, does mathematics study?" is not the same as the question "Do (some or all) of the nouns used in mathematical discourse refer to real objects?" The latter question was central to the indispensability argument for realism and is natural in considering whether complex numbers, for example, are fictions. But it has little relevance to the basic question of what mathematics studies. For comparison, the question "Does demography deal with quantitative variation in populations?" is little affected by whether "the average Londoner" is a real entity or a fiction that aids thinking about a population. We will consider in section 9 below fictionalist extensions of Aristotelian realism. True, it would be surprising if the most basic mathematical language, like "2" and "bigger than" failed to refer. It will be clear in the accounts to be given below what the authors think such language refers to.

\section{Mathematics as the "science of quantity"}

An Aristotelian realist philosophy of mathematics dominated from ancient times to the eighteenth century. It held that mathematics is the "science of quantity". Quantity, one of Aristotle's categories, was taken to be a real, observable property of the physical world as much as qualities were. (Biancani 1615, discussed in Park 2018, ch. 12; Barrow 1734, 10-15; Encyclopedia Britannica 1771, article 'Mathematics', vol. III 30-31; Jesseph 1993, ch. 1) Quantity was said to be divided into the discrete (studied by arithmetic) and the continuous (studied by geometry and later by the calculus). The origins of the theory are literally Aristotelian (Metaphysics bk 5 ch. 13, 1020a7-12). The quantity theory plainly gives an initially reasonable picture of at least elementary mathematics, with its emphasis on counting, 
measuring, and calculating with the resulting numbers. It promises direct answers to questions about what the object of mathematics is (certain properties of physical and possibly nonphysical things such as their size), and how those properties are known (the same way other natural properties of physical things are known - by perception in simple cases and inference from perception in more complex ones). It is as easy to perceive that the ratio of length to breadth of a rectangle is approximately double as it is to perceive that the rectangle is white.

Not much was heard of the realist quantity theory after 1800. A simplified version of it was defended by John Stuart Mill, as discussed below, but the criticisms of Mill made by Frege were generally thought to have decisively ruled out any such realist theory.

A strong point of the "science of quantity" theory is that it makes sense of measurement. Measurement is the most direct connection between mathematics and the world, as it directly assigns numbers to parts of the physical world (or more exactly their ratios), but has had a strangely low profile in the philosophy of mathematics.

The theory of measurement displays particularly clearly the difference between a Platonist and an Aristotelian approach to quantity. The foundational approach to measurement (in classical measurement theory, outside the philosophy of mathematics) sets up the problem with a Platonist bias, concentrating on "representation theorems" that describe the conditions under which quantities can be represented by numbers. (e.g. Savage and Ehrlich 1992) That poses the problem as if it is one about the association of numbers to parts of the world, which inevitably leads to a Platonist perspective.

But a closer look suggests an Aristotelian reinterpretation. What is it about the quantitative properties of the measured world that ensures that a representation by numbers exists? If, for example, we measure the length of an object by laying out unit rods beside it, the quantitative property of length exists prior to the representation and is the condition of its existence. As the Aristotelian maintains, the system of ratios of lengths, including the ratio of object to unit, exists in the physical things being measured, and measurement consists in identifying the ratios that are of interest in a particular case; the arbitrary choice of unit merely allows ratios to be converted to digital numerals for ease of calculation. (Bigelow and Pargetter 1990, 60-61) That in turn suggests an Aristotelian realist view of the real numbers arising in measurement: they are in the first instance spatio-temporally located relations of ratio. (Michell 2005; Michell 1994; Mundy 1987; Knapp 2014, ch. 2; Hossack 2020, ch. 8; relation to Aristotle in Crowley 1996) Irrational ratios can be instantiated as well as rational ones - for example, if physical space is real and perfectly Euclidean, as it could be, then $\pi$ is instantiated as the ratio of perfectly circular parts of space to their diameters (though of course measurable only approximately). 
That still leaves the quantity theorist with the task of precisely defining "quantity". Which properties exactly are quantitative (as opposed to say qualitative)?

Starting from Aristotle's concepts of what is "subject to more and less" and "divisible into parts", a possible answer can be based on the mathematics of order structures. (Franklin 2014b) A partial order (in mathematical terminology) is a binary relation that is reflexive, antisymmetric and transitive. A linear or total order is a partial order in which any two elements are comparable (for example, "greater than" among whole numbers). The most core or paradigmatic quantities are those comparable on at least some total order. One may more loosely call any (not necessarily linear) order structure a kind of quantity (in that it permits some comparisons on a kind of scale). Thus vectors and complex numbers can be called quantities in that all the real-number multiples of a fixed one form a linear order and are thus subject to comparison as "more or less". (Bigelow and Pargetter 1990, section 2.6; Bigelow 1988, part II(c); Leuenberger and Keller 2009).

When it comes to considering whether the science of quantity coincides with what we understand as mathematics, the inclusion in one direction seems convincing but that in the other direction not.

The theory of quantity as such looks uncannily like what we know as elementary mathematics. The science of discrete quantity really is arithmetic as we know it; the science of continuous variation is calculus and the theory of the continuum itself in the standard logical "construction of the continuum". What discrete and continuous quantities have in common is the kind of thing studied in Euclid's theory of ratios as well as order theory as such. Those are all well-known parts - extensive parts - of mathematics. The theory of how to find out the quantities possessed by actual parts of the real world is measurement theory, a kind of applied mathematics. There seems nothing to be said about quantity in general that is not mathematics.

On the other hand, the reverse inclusion is false. Not everything in modern mathematics is about quantity. That was explained by Euler when introducing his solution to the Bridges of Königsberg problem. Euler proved that it was impossible to walk over all the seven bridges once, without walking over at least one of them twice. (Euler 1735; Räz 2018) (Fig 1) 


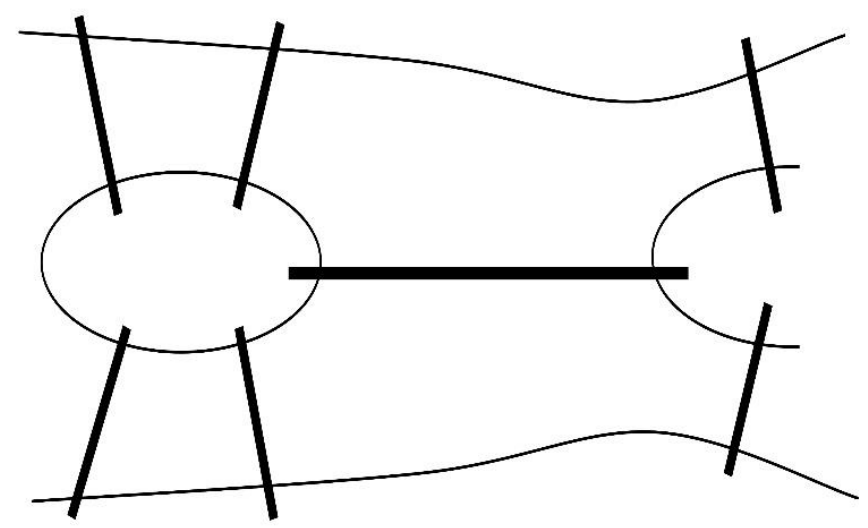

Fig 1: Euler's Seven Bridges of Königsberg

The result is intuitively about the "arrangement" or pattern of the bridges, rather than about anything quantitative like size or number. As Euler says, the result is "concerned only with the determination of position and its properties; it does not involve measurements." The length of the bridges and the size of the islands are irrelevant. All that matters is which land masses are connected by which bridges. Euler's result is now regarded as the pioneering effort in the topology of networks, and a paradigm example of now vast fields concerned with pure connections. Other large areas of modern higher mathematics, such as abstract algebra, are equally not reasonably classified as about quantity.

Nevertheless, any philosophy of mathematics should give an account of why a large part of actually existing mathematics does fall under the heading "the science of quantity".

\section{Mill's "empiricism", Frege's objection and Kessler's theory of number}

John Stuart Mill's theory, the best-known naturalist theory of mathematics, is normally presented as a long-exploded and easily dismissed view that mathematics consists of inductive generalizations from experience. The truth is a little more complex. For present purposes, what is of interest is not so much anything about the origins or certainty of mathematical knowledge, but Mill's account of what mathematics (at least arithmetic) is actually about.

His theory represented mathematics as an inductive science of the quantity of "aggregates", differing from other sciences such as chemistry simply in the generality of its subject matter, 
and learnable by manipulating physical objects. Arithmetic truths are just very general truths about quantity, arising from things being parted:

There are no such things as numbers in the abstract. Ten must mean ten bodies, or ten sounds, or ten beatings of the pulse. But though numbers must be numbers of something, they may be numbers of any thing ... All things possess quantity; consist of parts which can be numbered; and in that character possess all the properties which are called properties of numbers. (Mill 1862, bk. II ch. vi §2; discussions in Kitcher 1998; Bostock 2009 , ch. 3)

Frege argued that number could not be a property of things, as Mill thought, because many different numbers apply to a given heap, depending on how we choose to count (the Iliad is one poem or 24 books or a large number of verses). (Frege 1980, §22, p. 28) However, Mill was well aware of that. His actual statement of the nature of number is:

[Number is] ... some property belonging to the agglomeration of things which we call by the name; and that property is the characteristic manner in which the agglomeration is made up of, and may be separated into, parts ... When we call a collection of objects two, three, or four, they are not two, three, or four in the abstract, but two, three, or four things of some particular kind; pebbles, horses, inches, ... (1862, bk. III ch. xxiv §5.) That suggests the theory that number is a relation between an "agglomeration" or heap and the "kind" or universal that divides it into units. Glenn Kessler develops Mill's theory in exactly that way. A number is a "special sort of relation that holds between aggregates and properties that pick out parts of those aggregates." He writes, in reply to Frege's objection,

The question "Does 52 apply to this pack of cards?" lacks a determinate answer not because we have applied a number to an external object, but because we have mistaken a relation for a simple property ... in claiming that a certain aggregate $x$ contains 52 cards we are claiming that the numerical relation 52 holds between the aggregate $x$ and the property of being a card. (Kessler 1980, developed further in Forrest and Armstrong 1987; adopted in Franklin 2014a, ch. 3; a more extended Aristotelian reply to Frege in Irvine 2010)

Mill's theory and its successors, of course, only claim to be an account of whole numbers, not of mathematics overall. However, Gillies (2015) extends a loosely Millian account by taking advantage of the constructibility of (almost) all mathematics in set theory. If sets can be given a naturalistic, Aristotelian explanation, that should in principle account for all of mathematics. But some sets like a colony of bees are natural, being bound together by real relations such as proximity and functional relationship to the queen. Sets of that kind (though not arbitrary ones) 
play obvious roles in science. Gillies follows Maddy (1990 58-67; connections with natural language in Moltmann 2013) in holding that (many) sets are embodied, have causal powers and can be perceived; one can look in an egg carton and see that there are three eggs, thus perceiving a set of three eggs. (Maddy's later defection from an Aristotelian point of view was the result of issues unconnected with this view of simple sets; an Aristotelian reply in Park 2018, ch. 10).

Aristotelian accounts of the nature of sets are available which contrast with the Platonic view of them as sui generis abstracta, though they have not found general acceptance. Sets are particulars (since an individual set is not repeatable), so they need a different account from (repeatable) properties. Armstrong (1991) suggests that a set is the heap (mereological sum) of its singleton sets, and that the singleton set of $\mathrm{X}$ is the state of affairs of X's having some unitmaking property. (Other proposals listed in Paseau 2008) In any case, sets on an Aristotelian view are not physical objects, but a different category of being, one which can be (but need not be) realized in physical objects.

Millian theories thus have brighter prospects than has normally been supposed in the philosophy of numbers. Whether they can give a good account of other mathematical properties like ratio and symmetry is as yet less clear.

\section{The science of relations as such}

The theory that mathematics is especially about relations has long existed at the level of gnomic utterance and half-conscious tendency. It can be defended as a standalone explicit philosophy of mathematics.

Poincaré famously said, "mathematicians do not study objects, but the relations between objects; to them it is a matter of indifference if these objects are replaced by others, provided that the relations do not change." (Poincaré 1905, 20; similar in Russell 1903, ch. I §8) Relations are not "objects" in the sense of particulars, but repeatables of a certain kind (though of course they can, like colors, be objects in the sense of objects of study). Many shifts of perspective in the history of mathematics have involved moving to a more relational point of view. For example, to see functions not as formulas but rather as relations between domain and codomain (satisfying certain conditions) is not simply more abstract, but more purely relational. The success of category theory as an overarching perspective on mathematics resulted from its disengaging morphisms between objects from anything about the nature of the objects. (Mac Lane 1986; discussion in McLarty 2007, section 2) 
The theory that mathematics is simply the study of relations as such is defended by Robert Thomas. He suggests graph theory as an ideal context to appreciate the relational view:

If one models something with a graph ... one may be modelling activities by the edges of a graph whose vertices just represent the termination of the tasks, as in the criticalpath method, or one may be modelling places by vertices and the routes among them by edges, as in the travelling-salesman problem. But places and times are not significantly like the vertices, which have no character to be like. And activities and distances are not like edges, which are just pairs of vertices. In these and other cases, graphs represent naked relations with any quantitative elements as add-ons. (Thomas 2008, 253)

The defender of the science-of-relations theory of mathematics may be excused from giving an account of what relations are. Relations are a basic and familiar category of being (and not, for example, sets of ordered pairs). If mathematics really is the science of relations as such, that can be taken as bedrock.

Aristotelians insist too on the reality of relations. "Causality is the mark of being." We perceive mass because of its effect on us; likewise we perceive relations because of their effect on us. Indeed, our perceptual systems are set up to be particularly sensitive to relations. For example, the ratio of your height to mine is easily perceived if we stand next to each other. It is a difficult task for visual perception to extract invariant relations in the world, like shape and distance, from the more transient and even more relational play of projections on the retina from different perspectives, but the visual system is capable of extracting the invariant distant causes of the changing proximal effects. (Walsh and Kulikowski 1998, especially ch. 7 and 14) Symmetry perception involves seeing complex relationships.

The defender of the science-of-relations theory needs to show inclusions both ways: that all of mathematics can be seen in terms of relations; and that everything to do with relations in general is part of mathematics. The first of these tasks has attracted more attention than the second.

A philosophy of numbers that explains them without remainder in terms of relations - more so even than Kessler's theory described above - is that of Bigelow. His theory of whole numbers is that the number $n$ is the relation of $n$-fold mutual distinctness between objects. Thus the fact that $\mathrm{A}$ and $\mathrm{B}$ are two is just the fact that $\mathrm{A}$ is not the same individual as B. (Bigelow 1988, ch. 6)

Bigelow admits the reality of relations of proportion between quantities such as lengths but highlights instead the more purely relational (rational) ratios, which are a kind of relation between relations: the relation double holds between being-a-grandparent and being-a-parent, 
while the ratio 3:2 holds between being-a-great-grandparent and being-a-grandparent. (Bigelow 1988, ch. 11-12; Bigelow and Pargetter 1990, §8.3)

Thomas broadens the story to other areas of mathematics by looking at several incidents from the history of mathematics which suggest that all of classical mathematics can be seen as the pure study of relations. For example functions are a specific sort of relation, and differentiation came to be seen as a relation between functions. Abstract algebra is (or includes) the study of operations, a certain kind of ternary relation. (Thomas 2008, 254)

As to the reverse inclusion, one can ask what the theory of relations in general would look like if it were approached on its own terms, free from preconceptions. Would it be recognizably mathematics, or part of mathematics?

First, one would classify relations by their arity. Then for binary relations, one would naturally distinguish, in purely logical terms, between equivalence relations and order relations, functions and non-functions, and deal with composition of relations. The particular order relation characterised by having a start, one successor to every element, and never cycling (as described in Peano's axioms) is sufficient to give rise to arithmetic. Among ternary relations, binary operations are particularly important and give rise to algebraic structure ... The theory of relations as such begins to look like a very substantial part of mathematics.

Thus chess is mathematics because it is purely relational: chess pieces have no properties other than their roles in the game (their shapes being mere reminders of which piece they are). Chess is not normally taken to be serious mathematics because of the arbitrary choice of rules (and because what makes a good strategy in human chess is relative to an outside contingent fact, the intelligence of players). But the existence of a knight's tour of the chessboard, the solvability of newspaper chess puzzles with a given configuration and instruction "black to mate in two moves" and the abilities of AlphaZero in playing chess at superhuman levels are all pure mathematics.

\section{The science of structure}

Once it was agreed that examples like the Königsberg bridges and abstract algebra showed that "the science of quantity" was too narrow a definition of mathematics, it became natural to look for some other characterization of its subject matter. Higher mathematics came to be seen as the study of structure, a view associated with the name of Bourbaki, who classified structures into algebraic, topological and order structures. (1950; Corry 1992) 
In the philosophy of mathematics, Benacerraf's celebrated paper (1965) argued that (ordinal) arithmetic was the study of what progressions had in common and concluded (in language more Aristotelian than sometimes noticed by later writers) that arithmetic is "the science that elaborates the abstract structure that all progressions have in common merely in virtue of being progressions". What is important about the numbers is not their individual properties but "the structure which they jointly exhibit":

Numbers are not objects at all, because in giving the properties (that is, necessary and sufficient) of numbers you merely characterize an abstract structure ... the "elements" of the structure have no properties other than those relating them to other "elements" of the same structure. (Benacerraf 1965, 70)

From the Aristotelian realist point of view, that is suggestive and welcome, but two problems arise. The first is a tendency among many subsequent authors to interpret "structures" as some kind of Platonist entities like sets, as in the most prominent structuralist philosophy of mathematics, Shapiro's Philosophy of Mathematics: Structure and Ontology. (1997; nonAristotelian versions of structuralism are surveyed in Hellman 2007). That leads to the usual difficulties of Platonism, and obscures possible Aristotelian directions.

The second problem is the vagueness of meaning of "structure". The difficulty of defining "structure" has been the Achilles heel of structuralist philosophies of mathematics. (Pointed out in Colyvan 1998) One suggestion for a definition is:

A property is purely structural if it can be defined wholly in terms of the concepts same and different, and part and whole (along with purely logical concepts). (Franklin 2014a, 57; another attempt in Korbmacher and Schiemer 2018)

In short, a purely structural property is one definable in logic and mereology. For example, to be symmetrical with the simplest sort of symmetry is to consist of a part and another part which are the same in some respect. To say that mathematics is the science of "structure" is then just to say that it studies purely structural properties.

To show that all or much of mathematics is included in the science of structure and vice versa, the structuralist proposes to piggyback on the standard results on the constructability of most of mathematics in set theory, while reinterpreting sets and membership in terms of part and whole. For example, by transposing the standard set-theoretical definition of a topological space into mereology, it can be shown how the central notion of topology, that of an open set, is expressible solely in terms of parts: a collection of parts of an object can be called the open parts provided:

1. The empty part and the whole object are open 
2. Any sum of open parts is open

3. Any finite intersection of open parts is open

(Franklin 2014a, 61-62; examples from various areas of higher mathematics in Bell 2004) The point is to do without Platonic abstract objects such as sets, while being left with the reduction of mathematics to purely structural properties.

The relation of the "science of structure" theory of mathematics to the "science of relations" theory is a close one. Arguably they are actually the same theory rather than rivals, as it may be a mere matter of human perspective whether a subject matter is regarded as a "whole" or "system" with parts, or a disaggregated heap with relations among the constituents. If that is so, regarding something as a structured whole and investigating the relations between its parts is not really different from investigating the relations among many things. It is thus for mainly historical reasons that a perspective on "structure", coming from algebra and other areas of higher mathematics, is not normally counted as the same as the "relations" perspective based on the philosophical remarks of Poincaré and Russell.

That is confirmed by the much studied case of progressions, as in Benacerraf's paper. Whether one chooses to regard the progression as a whole or not does no work in the theory of arithmetic, which just proves theorems from Peano's postulates about all finite numbers (that is, constituents of progressions).

Both the science of relations view and the science of structure view call attention to realworld cases which contain a great deal of relations and structure, that is, complexity. Several semipopular books such as Gleick's Chaos (1987) and Waldrop's Complexity Theory (1992) promised to describe a new and all-encompassing "science of complexity". They described interdisciplinary work on such topics as evolutionary and self-organizing systems, but the results about what different systems had in common were mathematics, typically in dynamical systems theory. The "science of complexity" is part of mathematics, but there are simple structures as well.

\section{The science of patterns}

The idea that patterns in nature especially call for mathematical description is a staple of popular expositions of mathematics. Ian Stewart writes:

We live in a universe of patterns. Every night the stars move in circles across the sky. The seasons circle at regular intervals ... Tigers and zebras are covered in patterns of stripes ... Human mind and culture have developed a formal system of thought for 
recognizing, classifying and exploiting patterns. We call it mathematics. (Stewart 1995, 1; also Devlin 1994, 3; Steen, 1988)

As in the case of structure, examples and generalities have been much more prevalent than attempts to define precisely what counts as pattern, and to decide whether it differs from structure. In Stewart's examples, repetition is important, and indeed the most paradigmatic "patterns", like stripes and wallpaper patterns, do involve strict repetition. But regularities that would normally be called patterns can be less strict than that. Dennett makes use of the mathematical theory of compressibility: a series (of dots or numbers) is patterned, as opposed to random, if there is some way of describing it more efficient than simply copying it all bit by bit. Hence, "a pattern exists in some data - is real - if there is a description of the data that is more efficient than the bit map, whether or not anyone can concoct it." (Dennett 1991, 32-4; developed in Ladyman et al. 2007, 226-8) For our purposes, what is important is the combination of Aristotelian realism - patterns are an objective feature of nature - with their being defined wholly in mathematical terms.

Resnik in Mathematics as a Science of Patterns defines "pattern" so widely as to apparently include any structural property, including ones that are not purely structural, taking "specific notes (or sounds) in a musical pattern to be as much a part of the pattern as their arrangement." Mathematics however deals with pure patterns, for which a position in a pattern has "no distinguishing features other than those it has in virtue of being the particular position it is in the pattern to which it belongs." Resnik's account of patterns is officially largely Platonist, but is so qualified as to have strong Aristotelian tendencies. He writes:

Pattern-congruence is an equivalence relation whose field I take to include both abstract mathematical structures and arrangements of more concrete objects ... When a pattern and an arrangement of so-called concrete objects such as the pennies are congruent then I say that the arrangement instantiates the pattern ... The pennies thus instantiate the oneto-ten pattern. (Resnik 1999, 203-4)

So his "instantiation" is just the ordinary Aristotelian multiple realization of universals such as blue: there is something real and repeatable that occurs the same in different instances instantiability in multiple physical instances is just what distinguishes Aristotelianism from (standard, full) Platonism. Thus Resnik's theory is very naturally interpreted as an Aristotelian realism.

Theorists of pattern have not concentrated on the nature of numbers, but Resnik follows Benacerraf in taking the system of numbers as the prime example of a pattern. 


\section{Comparison of Aristotelian theories}

The different Aristotelian theories have arisen in different contexts. They are not rivals in the sense in which Platonism, nominalism and Aristotelianism are rivals in that only one can be true. If any theory has defects in comparison to others, it is more in failing to cover the whole field of mathematics than in giving a false account of the subject-matter which it takes as its paradigm.

Thus as we saw the "science of structure" theory and the "science of relations" theories are very close, to the extent of being reasonably seen as rebrandings of each other. "Pattern" and "complexity" are naturally seen as aspects of relations or structure: patterns are structures in which repetition is prominent, while complexity means a lot of structure, often with the suggestion of a range of kinds of parts and/or kinds of relations between them. Theories such as Mill's and Kessler's restrict themselves largely to an account of the natural numbers, so can fit into wider theories in various ways.

One might hope that an eirenic approach to the various realist perspectives coming from different areas would result in a synthesis of them which revealed the one true object of mathematics. It is certainly unsatisfying that such a synthesis seems to be currently not available. The obstacle lies in the non-purely-relational nature of quantities. The ratio of 1.57 metres to 0.35 metres is certainly a relation, but a relation of size. That ratio is a relation, and is for example the same as the relation between 15.7 grams and 3.5 grams, but it is not purely relational in the way symmetry is. It is hard to see what single overarching category could include size - surely basic to mathematics - and the wholly relational properties of set theory, graph theory and modern higher mathematics. While much of what there is to say about quantity comes from its structure as a linear or near-linear order, size is not itself purely structural. (Franklin 2014a, 63-66)

The "science of quantity" theory, based on the paradigm of elementary mathematics, thus differs significantly from the "science of relations or structure" theory, based on the paradigm of higher mathematics. A true unity between the two seems at present unattainable.

\section{Aristotelian realism with a dash of fictionalism}

As mentioned in section 2 above, questions about the subject-matter of mathematics are not the same as questions about whether all the nouns in mathematical discourse should be interpreted realistically. Language is a flexible instrument for dealing with reality and there is 
no problem with debating, within a realist perspective more generally, whether locutions such as "the Australian people", "the law of gravity" or "the national debt" refer to real entities or are merely ways of speaking that are helpful for thinking about other real entities. A fictionalist philosophy of all mathematical entities would be incompatible with Aristotelian realism, since a realist view of basics like ratio and symmetry were where Aristotelian realism started. But a fictionalist view of esoteric entities like complex numbers and higher infinities is quite compatible with the thrust of Aristotelian realism.

Bigelow (1988, chs 13-14) and Franklin (2014a, 231-3) in fact defended realist interpretations of the complex numbers, and Franklin took a hyperrealist view across the board, arguing that the only fictional entities in mathematics were zero and the empty set (which of their nature cannot be instantiated). Someone with down-to-earth Aristotelian tendencies might well blanch at that ontological prodigality. It is possible, and natural, to be realist about some of the older and more central entities of mathematics but to regard the more esoteric ones as fictions. For example, one could, inspired by Kronecker's remark that "God made the whole numbers, all the rest is the work of man" (Weber 1891-2,19) maintain that, say, whole numbers and ratios are natural and perceivable in the physical world, but, say, complex numbers and Hilbert spaces are fictions created by humans for some specifiable purpose.

There is a problem about where to draw the line, since there is no obvious stopping point. Nevertheless the pull of fictionalism about at least the higher mathematics is strong. The role of human invention in mathematics is well-known "from the inside". We understand why mathematicians think up new concepts for reasons apparently unconnected with any literal reality. Different flavors of Aristotelian realism come from choosing different stopping points on the road from hyperrealism to out-and-out fictionalism. That illustrates that Aristotelian realism is not a totalizing philosophy like Platonism or nominalism. Platonism claims that all mathematical entities are of the same nature, namely abstract objects, while nominalism claims they do not exist at all (and fictionalism claims they are all fictions). Aristotelian realism is different. It is a broad church. It advises looking at mathematical entities on a case by case basis.

\section{Objections to Aristotelianism}

Aristotelian approaches to mathematics face three main objections - objections which apply to all Aristotelian theories rather than to any of the particular versions just described. 
The first and best-known, applying just to number theory, is Frege's argument that numbers cannot be properties of real aggregates. It was considered with Aristotelian replies in section 4.

The second is that mathematics appears to deal sometimes with structures much too large to be instantiated, such as higher infinities, or possibly even huge finite numbers (if the universe is finite). (Koo 2016) As Balaguer (2008/2018) puts it, "set theory is committed to the existence of infinite sets that are so huge that they simply dwarf garden variety infinite sets, like the set of all the natural numbers. There is just no plausible way to interpret this talk of gigantic infinite sets as being about physical objects."

Aristotelians point out first that this problem is not unique to mathematics. If Newton's law of gravity connects mass, distance and force, it is not normally argued that it is not about physical reality just because some masses, distances and forces are too large to be instantiated in our world. Newton's law is about mass in general, and applies equally to describing actual masses and to predicting what would happen with masses not actually instantiated. If the law predicts something about masses bigger than those instantiated in the universe, that is not normally thought to require positing new "objects" with their own semantics. Computational chemistry too often deals with the properties of uninstantiated compounds (typically with a view to deciding which are worth manufacturing). It is the business of theoretical science (and mathematics) to deal with properties in general, and the business of observational science (and counting and measurement) to discover which properties are instantiated. The Aristotelian slogan is "instantiation is possible, but not necessary": it is for the world, not theory, to decide what properties are instantiated, but theory can study them all.

Nevertheless, Aristotelians need to provide an account of uninstantiated or unrealized properties, such as a possible uninstantiated shade of blue. That is an issue of general metaphysics rather than philosophy of mathematics. Franklin (2015) argues for a "semiPlatonist" Aristotelianism which admits a certain reality to uninstantiated universals, but not as Platonist abstract objects.

It is also possible, as argued in the previous section, for different Aristotelians to take different views on whether some of higher mathematics is in fact fictional. One position is that even the higher infinities could be realized in wood if the physical universe had enough dimensions; another is that all numbers beyond those instantiated in our finite universe are fictions - Aristotelianism can accommodate a range of views on how much of mathematics is really instantiated (provided that some is). This is an issue independent of which of the 
"schools" above is chosen, since any school may take more or less skeptical views of which of its entities become doubtfully instantiable when huge.

The third objection to Aristotelianism is that (applied) mathematics appears to deal with idealizations or mathematical models of the real world, such as perfect circles, rather than the messy and imperfect properties of actual matter. Aristotle reports Protagoras as "refuting" geometers by pointing out that hoops touch the ground at several points, unlike perfect circles. (Aristotle, Metaphysics 997b35-998a4) Aristotelians argue that that is not always the case for example, figure 1 displays the relevant structure of the Königsberg bridges exactly. And where it is true, the obscure philosophical notion of idealization can be replaced by the clear mathematical one of approximation. Modern mathematics can cope with the shapes of imperfect circles, which are as much geometrical shapes as perfect circles and whose areas are (provably) close to those of the perfect circles that approximate them. For example, if a real hoop has a shape which differs from a perfect circle of radius $1 \mathrm{~m}$ by no more than $1 \%(1 \mathrm{~cm})$ anywhere, then its area is provably within $2.1 \%$ of the area of the perfect circle. (Franklin 2014a, 222-9) Mathematics directly describes and proves facts about the shapes of physical objects.

Aristotelian realism is a viable alternative philosophy of mathematics to Platonism and nominalism. It is more in accord with naturalism than Platonism but unlike nominalism admits the reality of perceivable mathematical properties like ratio and symmetry.

The author states that there is no conflict of interest.

\section{References}

Armstrong, D.M. (1991). Classes are states of affairs. Mind, 100, 189-200.

Armstrong, D.M. (1997). A World of States of Affairs. Cambridge: Cambridge University Press.

Balaguer, M. (1998). Platonism and Anti-Platonism in Mathematics. New York: Oxford University Press.

Balaguer, M. (2008, revised 2018). Fictionalism in the philosophy of mathematics, Stanford Encyclopedia of Philosophy.

Barrow, I. (1734). The Usefulness of Mathematical Learning Explained and Demonstrated. London, repr. London: Cass, 1970. 
Bell, J.L. (2004). Whole and part in mathematics. Axiomathes, 14, 285-294.

Benacerraf, P. (1965). What numbers could not be. Philosophical Review, 74, 47-73.

Biancani (Blancanus), G. (1615). De mathematicarum natura dissertatio. Bologna, trans. G. Klima in P. Mancosu, Philosophy of Mathematics and Mathematical Practice in the Seventeenth Century (pp. 178-212). Oxford: Oxford University Press, 1996.

Bigelow, J. (1988). The Reality of Numbers: A Physicalist's Philosophy of Mathematics. Oxford: Clarendon.

Bigelow, J. and Pargetter, R. (1990). Science and Necessity. Cambridge: Cambridge University Press.

Bostock, D. (2009). Philosophy of Mathematics: An introduction. Malden, MA: Wiley.

Bourbaki, N. (1950). The architecture of mathematics. American Mathematical Monthly, 57, 221-232.

Brown, J.R. (2008). Philosophy of Mathematics: A Contemporary Introduction to the World of Proofs and Pictures. New York: Routledge.

Cheyne, C. and Pigden, C.R. (1996). Pythagorean powers. Australasian Journal of Philosophy 74, 639-645.

Colyvan, M. (1998). Review of Resnik, Mathematics as a Science of Patterns and Shapiro, Philosophy of Mathematics: Structure and Ontology, British Journal for the Philosophy of Science, 49, 652-656.

Colyvan, M. (2001). The Indispensability of Mathematics. Oxford: Oxford University Press.

Corry, L. (1992). Nicolas Bourbaki and the concept of mathematical structure. Synthese, 92, $315-48$.

Crowley, C.B. (1996). Aristotelian-Thomistic Philosophy of Measure and the International System of Units (SI). Lanham, Md: University Press of America.

Dennett, D. (1991). Real patterns. Journal of Philosophy, 88, 27-51.

Devlin, K.J. (1994). Mathematics: The Science of Patterns. New York: Freeman.

Encyclopaedia Britannica (1771). $1^{\text {st }}$ ed. Edinburgh.

Euler, L. (1735). Solutio problematis ad geometriam situs pertinentis, trans. in N. Biggs, E. Lloyd and R. Wilson (Eds), Graph Theory 1736-1936 (pp. 3-8). Oxford: Oxford University Press, 1976.

Forrest, P. and Armstrong, D.M. (1987). The nature of number. Philosophical Papers, 16, 165-186.

Franklin, J. (2011). Aristotelianism in the philosophy of mathematics. Studia Neoaristotelica, 8, 3-15.

Franklin, J. (2014a). An Aristotelian Realist Philosophy of Mathematics. Basingstoke: Palgrave Macmillan. 
Franklin, J. (2014b). Quantity and number. In D. Novotný and L. Novák (Eds), NeoAristotelian Perspectives in Metaphysics (pp. 221-244). London: Routledge.

Franklin, J. (2015). Uninstantiated properties and semi-Platonist Aristotelianism. Review of Metaphysics, 69, 25-45.

Frege, G. (1980). The Foundations of Arithmetic, trans. J.L. Austin, $2^{\text {nd }}$ revised ed. Oxford: Blackwell.

Gillies, D. (2015). An Aristotelian approach to mathematical ontology. In E. Davis and P.J. Davis (Eds), Mathematics: Substance and Surmise (pp. 147-176). Cham: Springer.

Giurfa, M., Eichmann, B. and Menzel, R. (1996). Symmetry perception in an insect. Nature, $382,458-461$.

Gleick, J. (1987). Chaos: Making a New Science. New York: Viking Books.

Hellman, G. (2007). Structuralism. In S. Shapiro (Ed), Oxford Handbook of Philosophy of Mathematics and Logic (ch. 17). Oxford: Oxford University Press.

Hossack, K. (2020). Knowledge and the Philosophy of Number: What Numbers Are and How They Are Known. London: Bloomsbury.

Irvine, A.D. (1990). Nominalism, realism and physicalism in mathematics. In A.D. Irvine (Ed), Physicalism in Mathematics (pp. ix-xxvi). Dordrecht: Kluwer.

Irvine, A.D. (2010). Frege on number properties. Studia Logica, 96, 239-260.

Jacquette, D. (2014). Toward a neoaristotelian inherence philosophy of mathematical entities. Studia Neoaristotelica, 11, 159-204.

Jesseph, D.M. (1993). Berkeley's Philosophy of Mathematics. Chicago: University of Chicago Press.

Jones, M. (2015). Review of J. Franklin, An Aristotelian Realist Philosophy of Mathematics, Philosophia Mathematica, 23, 281-288.

Kessler, G. (1980). Frege, Mill and the foundations of arithmetic. Journal of Philosophy, 77, 65-79.

Kitcher, P. (1998). Mill, mathematics and the naturalist tradition. In J. Skorupski (Ed), The Cambridge Companion to Mill (ch. 2). Cambridge: Cambridge University Press, 1998.

Knapp, R.E. (2014). Mathematics is About the World: How Ayn Rand's theory of concepts unlocks the false alternatives between Plato's mathematical universe and Hilbert's game of symbols. Lexington KY: CreateSpace.

Koo, A. (2016). Review of J. Franklin, An Aristotelian Realist Philosophy of Mathematics. Mathematical Intelligencer, 38(3), 81-84.

Korbmacher, J. and Schiemer, G. (2018) What Are Structural Properties? Philosophia Mathematica, 26, 295-323.

Ladyman, J., Ross, D., Spurrett, D. and Collier, J.G. (2007). Every Thing Must Go: Metaphysics Naturalized. Oxford: Oxford University Press. 
Lehrer Dive, L. 2003. An Epistemic Structuralist Account of Mathematical Knowledge. PhD thesis, University of Sydney.

Leuenberger, S. and P. Keller (2009). Introduction: the philosophy of vectors. Dialectica, 63, 369-380.

Liggins, D. (2010). Epistemological objections to Platonism. Philosophy Compass, 5, 67-77.

Linnebo, Ø. (2009, revised 2018). Platonism in the philosophy of mathematics. Stanford Encyclopedia of Philosophy.

Mac Lane, S. (1986). Mathematics: Form and Function. New York: Springer.

Maddy, P. (1990). Realism in Mathematics. Oxford: Clarendon Press.

McLarty, C. (2007). The last mathematician from Hilbert's Göttingen: Saunders Mac Lane as philosopher of mathematics. British Journal for the Philosophy of Science, 58, 77-112.

Michell, J. (1994). Numbers as quantitative relations and the traditional theory of measurement. British Journal for the Philosophy of Science, 45, 389-406.

Michell, J. (2005). The logic of measurement: a realist overview. Measurement, 38, 285-294.

Mill, J.S. (1862). A System of Logic, $5^{\text {th }}$ ed. London: Parker.

Moltmann, F. (2013). Reference to numbers in natural language. Philosophical Studies, 162, 499-536.

Mundy, B. (1987). The metaphysics of quantity. Philosophical Studies, 51, 29-54.

Newstead, A. and Franklin, J. (2012). Indispensability without Platonism. In Properties, Powers and Structures, ed. A. Bird, B. Ellis and H. Sankey (pp. 81-97). New York: Routledge.

Papineau, D. (2007, revised 2015). Naturalism. Stanford Encyclopedia of Philosophy.

Park, W. (2018). Philosophy's Loss of Logic to Mathematics: An Inadequately Understood Take-over. Cham: Springer.

Paseau, A. (2008). Motivating reductionism about sets. Australasian Journal of Philosophy, 86, 295-307.

Pincock, C. (2012). Mathematics and Scientific Representation. New York: Oxford University Press.

Poincaré, H. (1905). Science and Hypothesis. London: Walter Scott.

Räz, T. (2018). Euler's Königsberg: the explanatory power of mathematics. European Journal for Philosophy of Science, 8, 331-346.

Resnik, M.D. (1999). Mathematics as a Science of Patterns. Oxford: Clarendon Press.

Russell, B. (1903). The Principles of Mathematics. Cambridge: Cambridge University Press.

Savage, C.W. and Ehrlich P. (1992). Philosophical and Foundational Issues in Measurement Theory. Hillsdale, NJ: L. Erlbaum. 
Shapiro, S. (1997). Philosophy of Mathematics: Structure and Ontology. New York: Oxford University Press.

Steen, L.A. (1988). The science of patterns. Science, 240, 611-616.

Steiner, M. (1998). The Applicability of Mathematics as a Philosophical Problem.

Cambridge, Mass: Harvard University Press.

Stewart, I. (1995). Nature's Numbers: The Unreal Reality of Mathematics. New York: BasicBooks.

Thagard, P. (2019). Natural Philosophy: From Social Brains to Knowledge, Reality, Morality, and Beauty. Oxford: Oxford University Press.

Thomas, R.S.D. (2008). Extreme science: mathematics as the science of relations as such. In B. Gold and R. Simons (Eds), Proof and Other Dilemmas: Mathematics and Philosophy (pp. 245-263). Washington, DC: Mathematical Association of America.

Waldrop, M.M. (1992). Complexity: The Emerging Science at the Edge of Order and Chaos. New York: Simon \& Schuster.

Walsh, V. and Kulikowski, J. (Eds) (1998). Perceptual Constancy: Why Things Look as They Do. Cambridge: Cambridge University Press.

Weber, H.L. (1891-2). Leopold Kronecker. Jahresbericht der Deutschen MathematikerVereinigung, 2, 5-23. 